\title{
Bio removal of malachite green by mangrove-derived Aplanochytrium sp., KGA2512
}

\author{
Venugobal Gomathi, Kandasamy Saravanakumar and Kandasamy Kathiresan*
}

Centre of Advanced Study in Marine Biology, Faculty of Marine Sciences, Annamalai University, Parangipettai 608502 , India.

Accepted 19 April, 2013

\begin{abstract}
Effect of mangrove-derived Aplanochytrium sp., was studied for the removal of malachite green in aqueous solution under controlled experimental conditions. The dye removal was measured at regular interval by measuring its color intensity. This was confirmed further by Fourier Transform Infra Red (FTIR) and also to find out the change in the chemical groups. To enhance the dye removal, a statistical optimization was done by two phases of response surface methodology (RSM): (i) Plackett-Burman design for selection of the important process enhancing factors of dye removal, such as $\mathrm{pH}$, temperature, incubation period, dye concentration, glucose, peptone and yeast extract and (ii) Centre composite design to study optimized condition, interaction and combined effect of the selected factors on dye removal. Aplanochytrium sp., was found to remove the azo-dye significantly up to $86.32 \%$ within five and half days of incubation under optimized conditions of $\mathrm{pH} 7.8$ and at temperature of $27.8^{\circ} \mathrm{C}$. This study proved that mangrove-derived Aplanochytrium sp., was found promising for its potential of synthetic dye removal
\end{abstract}

Key words: Mangroves, bioremoval, malachite green, Aplanochytrium sp and response surface methodology.

\section{INTRODUCTION}

Chemical dyes are widely used in many industries related to paper, printing, textile and leather industries (Korbahti and Rauf, 2008a). After usage of the dyes, the remaining dye effluents are directly discharged into the river, sea or lake. The discharged dyes, in particular azo-dyes, are of great environmental concern. During natural removal of the azo-dyes, some toxic chemicals are produced and they are highly carcinogenic and mutagenic to the flora and fauna (Bali et al., 2004).

In order to remove the toxic dye chemicals, many treatment methods are applied. The methods include flocculation, coagulation, activated carbon adsorption, membrane filtration and sedimentation. However, these methods are not successful due to several reasons: (i) the chemicals are only partially degraded; (ii) the azo-dyes are converted into the toxic metabolites and (iii) the toxic chemi-cals are just converted to the secondary solid wastes due to their complex binding structure; and this secondary waste has to be either treated again or dumped as such (Behnajady et al., 2006).

The biological treatments in the dyes are more important to the dye removal process for removing the toxic compounds (Peralta-Hernandez et al., 2008). Microorganisms are capable of removing azo-dyes in vallismortis and B. megaterium (Tony et al., 2009a and b), Ganoderma sp. (Mohammadian Fazli et al., 2010), Proteus vulgaris and Micrococcus glutamicus (Saratale et al., 2010a), Oscillatoria curviceps (Balakrishnan Priya et al., 2011), Bacillus lentus (Chetan et al., 2011), Sphingomonas paucimobilis (Lamia Ayed et al., 2011), Halomonas sp. (Balamurugan et al., 2011), and Schizophyllum sp. (Wenzhong Tang et al., 2011). 
The classical and conventional methods of studying the dye removal as influenced factors individually and in combinations are difficult. These methods also consume more time and require numerous amounts of experiments to represent the combinational effects of the parameters. With the large number of experiments, the results will be unreliable. These limitations of conventional methods can be solved by optimizing the parameters using the response surface methodology (RSM). RSM is a statistical tool for determining the optimum conditions for a target product. The application of statistical experimental design techniques can improve product's yield, reduce process variability and experimental time (Montgomery, 1997). The present investigation therefore, was made to study the dye-degrading effect of Aplanochytrium sp., and to optimize the factors that were responsible for dye removal with the following objectives: to find out the potential Aplanochytrium sp., for degrading the dye using plating methods, and identify the important parameters for the dye removal by using statistical model (Plackett-Burman design of RSM) and optimize the identified parameters by using statistical model (center composite design of RSM).

\section{MATERIALS AND METHODS}

\section{Preparation of dye stock solution}

Malachite green dye was prepared by dissolving $250 \mathrm{mg}$ of the dye powder in $100 \mathrm{ml}$ of sterilized distilled water with concentration of $2.5 \mathrm{mg}$ per $\mathrm{ml}$. From the stock, different concentrations of the dye solution were incorporated in the culture medium.

\section{Bioremoval of the azo-dye by Aplanochytrium sp.}

The pure strain of Aplanochytrium sp., KGA2512 (JQ284385) was maintained at -4 to $1^{\circ} \mathrm{C}$ on glucose peptone agar slants (Gomathi, 2009). For experimental purpose, Aplanochytrium sp. was asepticcally transferring to the $100 \mathrm{ml}$ glucose peptone broth medium in $250 \mathrm{ml}$ Erlenmeyer flasks. The flasks were incubated at $27 \pm 1^{\circ} \mathrm{C}$ in shaking incubator. The biological treatment experiments were performed in the Erlenmeyer flasks containing $250 \mathrm{ml}$ of the synthetic dye solution and live Aplanochytrium sp., biomass under controlled environment. At appropriate reaction times, cell-free culture filtrate samples were drawn and the colour intensity was determined by using a spectrophotometer.

\section{Determination of dye removal based on colour intensity of dye solution}

$5 \mathrm{ml}$ of culture filtrate from each group of flasks was drawn and centrifuged at 3,000 rpm for $60 \mathrm{~min}$. After centrifugation, the supernatant was collected and the absorbance was determined at 640 $\mathrm{nm}$ by using a spectrophotometer (Elico, Model 301). This was done for 20 days at an interval of three days. The change of absorbance value was converted into concentration of dye value for determining the removal of malachite green dye.

\section{FT-IR analysis}

Fourier transform infrared (FT-IR) spectroscopy was performed in the presence of toxic chemicals in the degraded dye samples. For FT-IR analysis, biological treatment process was performed with $250 \mathrm{ml}$ solution containing $25 \mathrm{mg}^{-1} \mathrm{I}^{-1}$ of malachite green and $5 \mathrm{~g}$ of Aplanochytrium sp., biomass. At the reaction times of $0 \mathrm{~h}$ (control) and 20 days, samples were taken and the biological removal products were extracted with $30 \mathrm{ml}$ of diethyl ether in three times, then crystallized and used for FT-IR analysis.

\section{Laccase enzyme assay}

To find out the reason of the potential bioremoval, the laccase activity was tested. It was assessed by growing the fungi on glucose yeast peptone agar medium amended with 1-naphthol, $0.005 \%(\mathrm{pH}, 6)$ and incubated. On oxidation of 1 -naphthol by laccase, the medium changed from clear to blue, indicating positive reaction for the presence of laccase.

\section{Selection of the important parameters for bioremoval of dye using Plackett-Burman design}

To select the important medium constituents and environmental factors, the Plakett-Burman design (Plackett and Burman, 1946) with the 16 runs was used. The culture medium constituents and environmental parameters tested were $\mathrm{pH}$, temperauture, incubition period, dye concentration, glucose $\left(\mathrm{mg}^{-1} \mathrm{I}^{-1}\right)$, peptone and yeast extract. From these, important process influencing factors were selected. The experimental design along with the experimental and statistically predicted response of the dye removal is presented in the Table 1. Finally, the selection was made based on positive coefficient values. The effect of individual parameters on dye removal was calculated by the following equation:

$\mathrm{E}=\left(\Sigma \mathrm{M}_{+}-\Sigma \mathrm{M}_{-}\right) / \mathrm{N}$

Where, $E$ is the effect of parameter under study and $M(+)$ and $M(-)$ are responses of dye removal in trials, and $\mathrm{N}$ is the total number of trials. The selected factors were used for further optimization study.

\section{Optimization of the biological dye removal}

The significant changes were observed with $\mathrm{pH}$, temperature, incubation period, yeast extract. This indicated that importance of these parameters on dye removal (Table 2). These parameters were selected for the further optimization. For the optimization, 30 runs of center composite design were used. Of these, each factor was assessed at five coded levels $(-2,-1,0,+1$ and +2$)$. In the whole experiment, minimum and maximum actual values of the production medium were used and are presented in Table 2. The response value $(\mathrm{Y})$ in each trial was the average of the duplicates (Table 3).

\section{Statistical analysis and modeling}

The obtained data from RSM on dye removal were subjected to analysis of variance (ANOVA). The experimental results of RSM were fit via the response surface regression procedure, using the following second order polynomial equation.

$Y i=\beta_{0}+\Sigma_{i} \beta_{i} X_{i}+\Sigma_{i} \beta_{i i} X_{i}^{2}+\Sigma_{i j} \beta_{i j} X_{i} X_{j}$

Where, $\mathrm{Yi}$ is the predicted response, $\mathrm{X}_{\mathrm{i}} \mathrm{X}_{\mathrm{j}}$ are independent variables, $\beta_{0}$ is the offset term, $\beta_{i}$ is the $i^{\text {th }}$ linear coefficient, $\beta \mathrm{ii}$ is the $\mathrm{i}^{\text {th }}$ quadratic coefficient and $\beta_{\mathrm{ij}}$ is the $\mathrm{ij}^{\text {th }}$ interaction coefficient. However, in this experiment, the independent variables were coded as 
Table 1. Selection of dye removal responsible parameters and predicted and actual percentage of dye removal by using Plackett-Burman experimental design.

\begin{tabular}{cccccccccc}
\hline Number & A & B & C & D & E & F & G & \multicolumn{2}{c}{ Percentage (\%) of dye removal } \\
\cline { 8 - 9 } & & & & & & & & Experimental & Predicted \\
2 & 8.8 & 20 & 0 & 10 & 2 & 2 & 1 & 0.9401 & -1.88776 \\
3 & 7.2 & 20 & 0 & 10 & 4 & 2 & 4 & 0.6996 & 4.55945 \\
4 & 26 & 0 & 10 & 4 & 4 & 1 & 0.7702 & 3.598063 \\
5 & 8.2 & 26 & 0 & 10 & 2 & 4 & 4 & 0.2321 & -3.62775 \\
6 & 7.8 & 20 & 10 & 10 & 4 & 4 & 4 & 48.3 & 25.47214 \\
7 & 8.2 & 20 & 10 & 10 & 2 & 4 & 1 & 21.35 & 47.96586 \\
8 & 7.8 & 26 & 10 & 10 & 2 & 2 & 4 & 45.138 & 42.81075 \\
9 & 8.2 & 26 & 10 & 10 & 4 & 2 & 1 & 46.6706 & 3.258363 \\
10 & 7.8 & 20 & 0 & 50 & 2 & 4 & 4 & 0.4305 & -1.19445 \\
11 & 8.2 & 20 & 0 & 50 & 4 & 4 & 1 & 2.6654 & -1.88496 \\
12 & 7.8 & 26 & 0 & 50 & 4 & 2 & 4 & 0.9429 & 3.09105 \\
13 & 8.2 & 26 & 0 & 50 & 2 & 2 & 1 & 0.2312 & 30.13956 \\
14 & 7.8 & 20 & 10 & 50 & 4 & 2 & 1 & 27.3117 & 53.39335 \\
15 & 8.2 & 20 & 10 & 50 & 2 & 2 & 4 & 57.2532 & 43.26244 \\
16 & 7.8 & 26 & 10 & 50 & 2 & 4 & 1 & 46.0903 & 57.52155 \\
\hline
\end{tabular}

A , pH; B , temperauture (C); C, incubation period (Days); D, dye concentration (mg. $\left.I^{-1}\right)$; E, glucose $\left(m g . I^{-1}\right)$; F, peptone $\left(m g . I^{-1}\right) ; G$, yeast extract $\left(m g . I^{-1}\right)$.

Table 2. Statistical parameters for selected the linear polynomial model using Plackett-Burman design.

\begin{tabular}{|c|c|c|c|c|}
\hline Parameter & Coefficient & SE Coefficient & Actual & Probability \\
\hline $\mathrm{pH}$ & 22.04297 & 2.392449 & 22.04 & 0.013 \\
\hline Temperature $\left({ }^{\circ} \mathrm{C}\right)$ & 0.802506 & 2.392449 & 0.80 & 0.007 \\
\hline Incubation period (days) & 2.174156 & 2.392449 & 2.17 & 0.045 \\
\hline Dye concentration (mg. ${ }^{-1}$ ) & -0.17897 & 2.392449 & 21.18 & 0.012 \\
\hline Glucose $\left(\right.$ g..$\left.^{-1}\right)$ & -0.530394 & 2.392449 & 1.53 & 0.587 \\
\hline Peptone (mg.l $\left.{ }^{-1}\right)$ & -0.584794 & 2.392449 & 0.58 & 0.829 \\
\hline Yeast extract (mg.l $\left.{ }^{-1}\right)$ & 12.35544 & 2.392449 & -0.36 & 0.008 \\
\hline
\end{tabular}

$X_{1}, X_{2}, X_{3}$ and $X_{4}$. Thus, the second order polynomial equation can be presented as follows:

$Y=\beta_{0}+\beta_{1} X_{1}+\beta_{2} X_{2}+\beta_{3} X_{3}+\beta_{4} X_{4}+\beta_{11} X_{1}^{2}+\beta_{22} X_{2}^{2}+\beta_{33} X_{3}^{2}+\beta_{44}$ $X_{4}^{2}+\beta_{12} X_{1} X_{2}+\beta_{13} X_{1} X_{3}+\beta_{14} X_{1} X_{4}+\beta_{23} X_{2} X_{3}+\beta_{24} X_{2} X_{4}+\beta_{34} X_{3} X_{4}$

Statistical software namely the Design expert (8.0.6 package) was used for the regression analysis and to plot the response surface graphs of the experimental data. The statistical significance of the model equation and the model terms were evaluated by the Fisher's test. The quality of fit in the second-order polynomial model equation was expressed by the coefficient of determination $\left(R^{2}\right)$ and the adjusted $R^{2}$. The fitted polynomial equation was then expressed in the form of three-dimensional surface plots, in order to illustrate the relationship between the responses and the experimental levels of each of the variables used in this experiment. The point optimazation method was employed in order to optimize the level of each variable for maximum dye removal. The combination of different optimized variables, which yielded the maximum response, was determined in an attempt to verify the validity of the model.

\section{RESULTS}

The removal of the malachite green dye by Aplanochytrium

sp., was tested and in this connection, the presence of oxidative enzyme laccase was tested in the culture filtrate of Aplanochytrium sp. The presence of laccase enzyme was observed in the culture filtrate (Figure 1a). Before the dye decolouration and after decolouration processes, dye concentration was determined by using a spectrophotometer. It revealed $73.23 \%$ of dye decolouration (Figure $1 b$ ).

\section{Selection of important factors for dye removal using Plackett-Burman design}

The important factors for the maximum dye removal were selected by using 16 runs of the Plackett-Burman design and data are presented in the Table 1 . The $F$ value of 


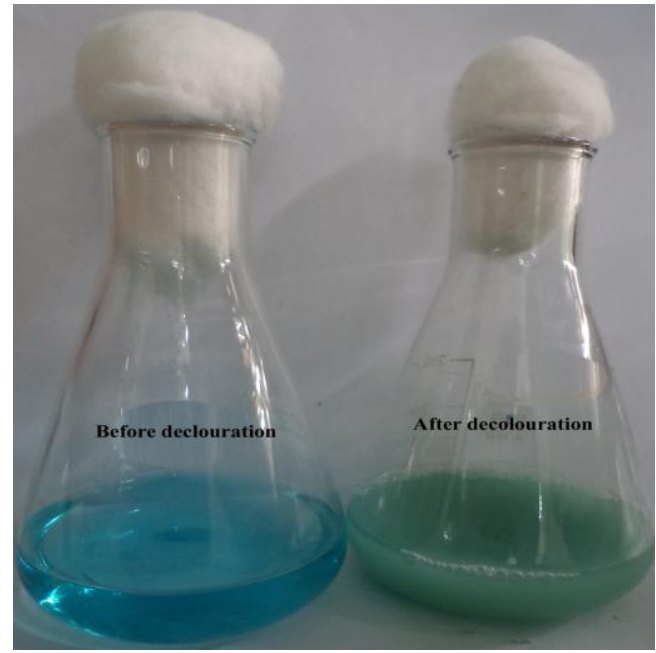

Figure 1a. A view of dye decolouration before the addition of Aplanochytrium sp. and with Aplanochytrium sp. after 20 days of incubation.

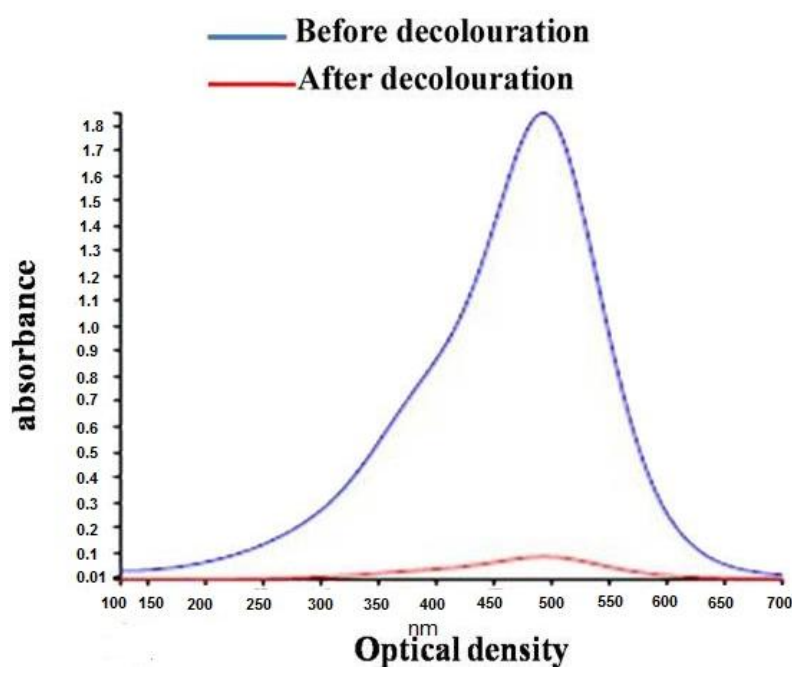

Figure 1b. Spectrophotometer determination of dye removal by Aplanochytrium sp.

8.56 implies that the model was significant. The probability value of $<0.0143$ indicates model terms were significant. The magnitude of the effects indicated the level of the significance of the variables on dye removal. The selection of the important factors was made based on the significant response on dye removal and positive coeffi-cients values (Table 2).

\section{RSM approach for optimization of dye removal}

Center composite design (CCD) was used to design the experiments to evaluate the interactive effects of process parameters for optimizing dye removal by Aplanochytrium sp. The empirical relationship between the response and various input variables in the RSM approach obtained from the center composite model along with the predicted and experimental response of the percentage of the dye removal is presented in Table 3. The statistical significance was tested with the individual and interactions effects of variables at various levels of concentration on the dye removal probability values are shown in Table 4 based on Fisher's test and analysis of variance fitted to second order polynomial equation. The probability value of $<0.05$ revealed that the variables were statistically significant (Montgomery, 1997). The variables such as $\mathrm{pH}$, temperature and incubation period were observed as significant parameters for the dye removal. Regarding interactions of the parameters, the interactions of temperature and incubation period, temperature and yeasts extract were found significant indicating that the variables were vital for dye removal process. The parameters were then fitted into second order polynomial equation as follows:

Percentage of dye removal $=83.20+0.97 \mathrm{~B}+1.29 \mathrm{C}+$ $21.52 D+0.66 A B+0.62 A C-0.57 A D+0.56 B C+3.09 B D$ $-0.81 C D$

The determinations of the model accuracy was tested by second order polynomial model and significant F-Value $(F=6.34$, degree of freedom $=14, P<0.0005)$ and a low value of standard deviation $(0.17)$ between the measured and modeled results were observed. This showed that the equation adequately represented actual relationship between the response (percentage of the dye removal) and significant variables. High value of $R^{2}(0.72)$ was very close to the predicted value of $R^{2}$ which indicated a high dependence and correlation between the observed and the predicted values of response. The lack-of-fit term was non-significant as it was desired. The non-significant value of lack of fit observed was 8.112 more than 0.05 showing that the quadratic model was valid for the present study.

Validation of the model was also carried out by plotting standard error in response as a function of a pair of factors. A plot of the standard errors in bioremoval of the dye as a function of temperature and $\mathrm{pH}$ is shown in Figure $2 a, b, c$ and $d$. The shape of the standard error plot was not only found to fit on the design points but also the polynomial showed low and flat errors exhibiting circular contours and symmetrical shape around the centroid, representing best condition. The standard error value around the centroid was 0.401 , which was the best value. The inferences obtained from the response surface methodology based on the CCD experimental design model in relation to dye removal by Aplanochytrium sp., with respect to each variable are as follows.

\section{Effect of temperature and incubation period on dye removal}

The interactions and individual effects of the temperatures 
Table 3. Central composite design matrix for the experimental design and predicted and actual responses for Azo-dye removal.

\begin{tabular}{|c|c|c|c|c|c|c|}
\hline \multirow{2}{*}{ Standard } & \multirow{2}{*}{$\mathrm{pH}$} & \multirow{2}{*}{ Temperature $\left({ }^{\circ} \mathrm{C}\right)$} & \multirow{2}{*}{ Incubation period (Day) } & \multirow{2}{*}{$\begin{array}{c}\text { Yeast extract } \\
\left(\mathrm{mg.} \mathrm{I}^{-1}\right)\end{array}$} & \multicolumn{2}{|c|}{$\%$ of dye removal } \\
\hline & & & & & Experimental & Predicted \\
\hline 1 & 7.8 & 23 & 5.5 & 1 & 5.3 & 13.84 \\
\hline 2 & 8.2 & 23 & 5.5 & 1 & 5.52 & 12.08583 \\
\hline 3 & 8 & 26 & 1 & 5.5 & 5.2 & 7.824167 \\
\hline 4 & 8 & 26 & 5.5 & 1 & 5.1 & 8.705 \\
\hline 5 & 8 & 23 & 5.5 & 5.5 & 68.52 & 56.16583 \\
\hline 6 & 8.2 & 23 & 5.5 & 10 & 68.5 & 56.87167 \\
\hline 7 & 8 & 23 & 5.5 & 5.5 & 55.6 & 52.37 \\
\hline 8 & 8 & 20 & 5.5 & 10 & 62.54 & 55.71083 \\
\hline 9 & 8 & 26 & 10 & 5.5 & 1.59 & 15.2275 \\
\hline 10 & 8 & 23 & 1 & 1 & 5.12 & 15.75333 \\
\hline 11 & 7.8 & 23 & 10 & 5.5 & 2.53 & 21.56167 \\
\hline 12 & 8.2 & 26 & 5.5 & 5.5 & 5.56 & 24.7225 \\
\hline 13 & 8.2 & 23 & 10 & 5.5 & 50.52 & 54.31833 \\
\hline 14 & 7.8 & 20 & 5.5 & 5.5 & 53.12 & 57.30417 \\
\hline 15 & 7.8 & 23 & 5.5 & 10 & 62.63 & 62.8725 \\
\hline 16 & 8 & 23 & 10 & 1 & 69.63 & 68.49333 \\
\hline 17 & 8 & 20 & 1 & 5.5 & 18.56 & 9.520833 \\
\hline 18 & 7.8 & 26 & 5.5 & 5.5 & 18.56 & 13.3875 \\
\hline 19 & 8 & 23 & 5.5 & 5.5 & 52.1 & 47.5175 \\
\hline 20 & 8 & 23 & 10 & 10 & 62.32 & 52.69083 \\
\hline 21 & 8 & 26 & 5.5 & 10 & 55.6 & 20.80583 \\
\hline 22 & 8 & 23 & 5.5 & 5.5 & 86.32 & 106.9025 \\
\hline 23 & 8 & 20 & 10 & 5.5 & 0 & 13.45917 \\
\hline 24 & 8.2 & 23 & 1 & 5.5 & 55.3 & 27.62917 \\
\hline 25 & 8.2 & 20 & 5.5 & 5.5 & 82.5 & 83.195 \\
\hline 26 & 8 & 20 & 5.5 & 1 & 85.12 & 83.195 \\
\hline 27 & 8 & 23 & 5.5 & 5.5 & 82.12 & 83.195 \\
\hline 28 & 7.8 & 23 & 1 & 5.5 & 82.53 & 83.195 \\
\hline 29 & 8 & 23 & 1 & 10 & 83.32 & 83.195 \\
\hline 30 & 7.8 & 23 & 5.5 & 1 & 83.58 & 83.195 \\
\hline
\end{tabular}

Table 4a. Analysis of variance table (ANOVA) for response surface methodology of main effects and interacting effects of parameters in quadratic model.

\begin{tabular}{|c|c|c|c|c|c|}
\hline Source & Sum Square & df & Square & F Value & P- value Prob $>$ F \\
\hline Model & 25770.12 & 14 & 1840.723 & 6.344683 & $0.0005^{* *}$ \\
\hline A-pH & 22.42667 & 1 & 22.42667 & 0.077301 & $0.007^{\star *}$ \\
\hline B-Temperature & 40.14507 & 1 & 40.14507 & 0.138374 & $0.071^{*}$ \\
\hline C-Incubation period & 11118.95 & 1 & 11118.95 & 38.32529 & $0.0001^{* *}$ \\
\hline D-yeast extract & 301.1834 & 1 & 301.1834 & 1.038132 & $0.324 \mathrm{NS}$ \\
\hline$A B$ & 6.943225 & 1 & 6.943225 & 0.023932 & $0.879 \mathrm{NS}$ \\
\hline$A C$ & 6.0516 & 1 & 6.0516 & 0.020859 & $0.887 \mathrm{NS}$ \\
\hline$A D$ & 5.1984 & 1 & 5.1984 & 0.017918 & $0.895 \mathrm{NS}$ \\
\hline $\mathrm{BC}$ & 4.9284 & 1 & 4.9284 & 0.016987 & $0.0498^{*}$ \\
\hline BD & 152.5225 & 1 & 152.5225 & 0.525721 & $0.0479^{*}$ \\
\hline CD & 10.46523 & 1 & 10.46523 & 0.036072 & $0.851 \mathrm{NS}$ \\
\hline A2 & 8822.995 & 1 & 8822.995 & 30.41148 & $0.0001^{\star \star \star}$ \\
\hline
\end{tabular}


Table 4a. Contd.

\begin{tabular}{lccccc}
\hline B2 & 1877.148 & 1 & 1877.148 & 6.470237 & $0.0225^{*}$ \\
C2 & 641.2591 & 1 & 641.2591 & 2.21032 & $0.1578 \mathrm{NS}$ \\
D2 & 6728.789 & 1 & 6728.789 & 23.19308 & $0.0002^{* *}$ \\
Residual & 4351.808 & 15 & 290.1205 & & \\
Lack of Fit & 4345.857 & 10 & 434.5857 & 365.1766 & $0.231 \mathrm{NS}$ \\
Pure Error & 5.95035 & 5 & 1.19007 & & \\
Core Total & 30121.92 & 29 & & & \\
\hline
\end{tabular}

***,**,* Statistically significant at $p<0.0001, p<0.01$ and $p<0.05$ NS, Non-significant.

Table 4b. FTIR of malachite green before removal showing peaks and their corresponding bonds and name of chemical groups.

\begin{tabular}{cll}
\hline Peak & Bond & Group \\
\hline 435.91 & S-S & Sulfide groups \\
464.84 & & \\
503.42 & C-I & Aliphatic halogenated compounds \\
547.78 & $\mathrm{C}-\mathrm{Br}$ & \\
563.21 & $\mathrm{C}-\mathrm{H}, \mathrm{S}-\mathrm{S}$ & Alkene, Polysulfides \\
619.15 & $\mathrm{CH}-\mathrm{S}$ & Thio ethers \\
659.66 & $\mathrm{C}$ - & Tertiary amine \\
1128.36 & $\mathrm{~N}$ & Imino group \\
1624.06 & $\mathrm{C}=\mathrm{N}$ & Alkynes,Amines \\
2345.44 & $\mathrm{C} \equiv \mathrm{C}, \mathrm{C} \equiv \mathrm{N}$ & Alkene \\
2866.22 & $\mathrm{C}-\mathrm{H}$ & Methyl asymmetric stretch \\
2931.8 & $\mathrm{C}-\mathrm{H}$ stretch & Alcohol \\
3421.72 & $\mathrm{O}-\mathrm{H}$ stretch &
\end{tabular}

and incubation period were tested on dye removal by the RSM model and the results are shown in the contours and $3 \mathrm{D}$ plots. The temperature and incubation period interaction was significant (F value-0.016., P-value 0.04) for the statistical optimization of the parameters and the perturbation was observed by the way of increased and decreased levels of the parameters using the RSM surface model. It indicated that the statistical optima for the potential dye removal were temperature of $32.16^{\circ} \mathrm{C}$ and incubation period of 20 days (Figure $3 d$ ).

\section{Effect of temperature and yeast extract on dye removal}

The interactions and individual effects of the temperature and processing time were tested on dye removal by the RSM model and the results are shown in the contours and 3D plots. The yeast extract and temperature interactions were significant ( $\mathrm{F}$ value-0.54, $\mathrm{P}-0.042)$ for the statistical optimization of these parameters. The perturbation was observed by the way of increased and decreased levels of the parameters using the RSM surface model. It indicated that the statistical optima for the potential dye removal was at yeast extract of $5.62 \mathrm{mg}^{-1}$ and temperature of $27.03^{\circ} \mathrm{C}$ (Figure $3 \mathrm{e}$ ), and other second order interactions were not significant with dye removal. The results are presented in the contours and 3D plots (Figure 4 A - C, F).

The optimal conditions for dye removal process were $\mathrm{pH} 6.97$, temperature of $32.16^{\circ} \mathrm{C}$, incubation period of 20 days and yeast extract of $5.62 \mathrm{mg}^{-1} \mathrm{I}^{-1}$ (Figure 2d). Under these optimal conditions, the maximum dye removal of $84.59 \%$ was obtained and it was $9 \%$ higher than the normal method of removal of azo-dye.

\section{DISCUSSION}

The present study reported for the first time that thraustochytrids could be able to degrade azo-dye. The laccase enzyme capable of degrading the dye was found to be present in the culture filtrate of thraustochytrids. Other dyedegrading microbes are also known for the pro-duction of 


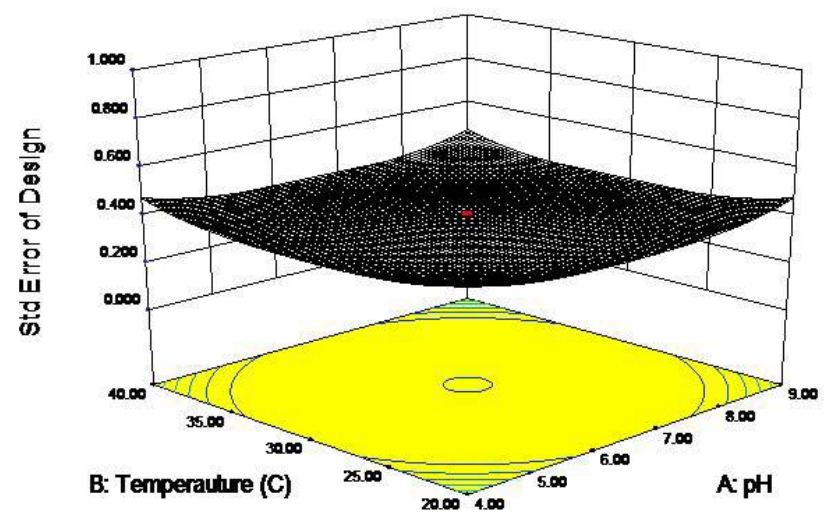

a

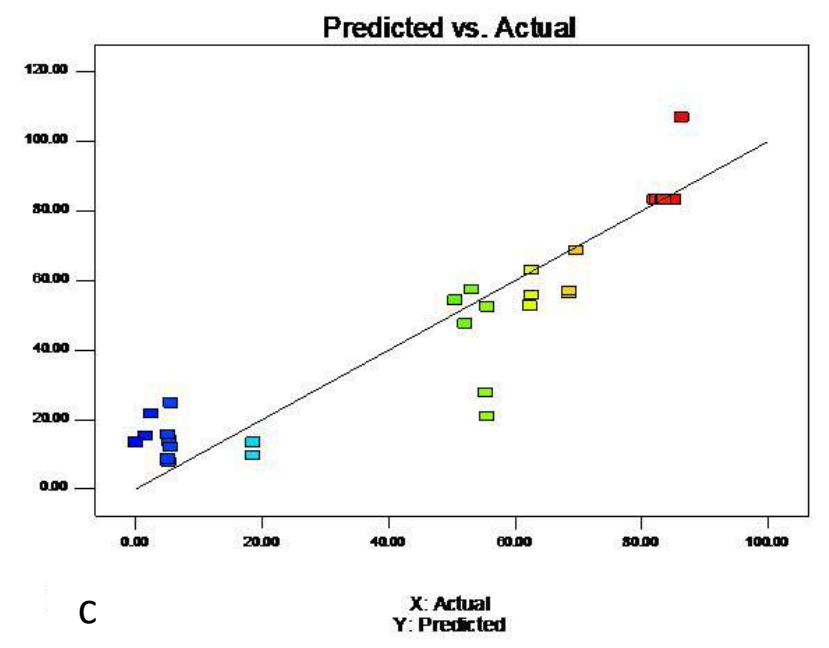

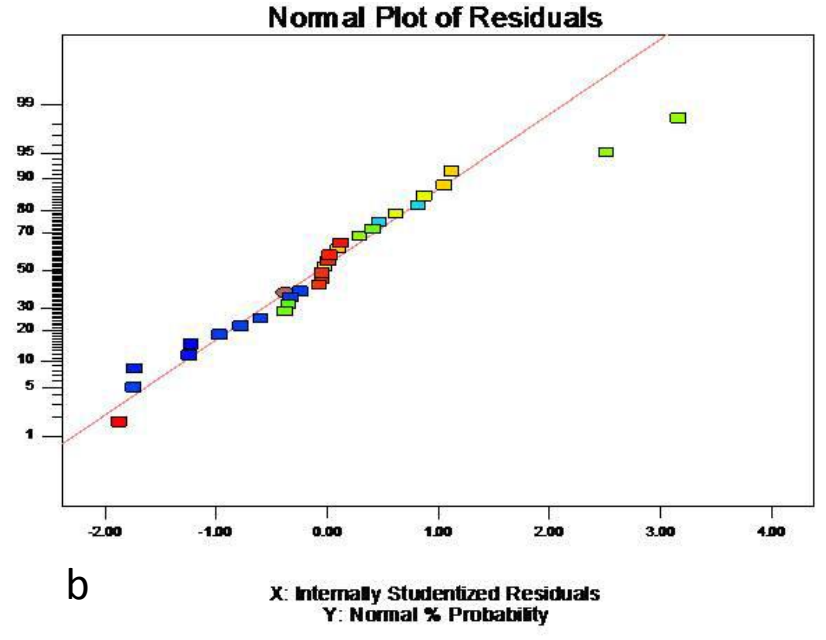

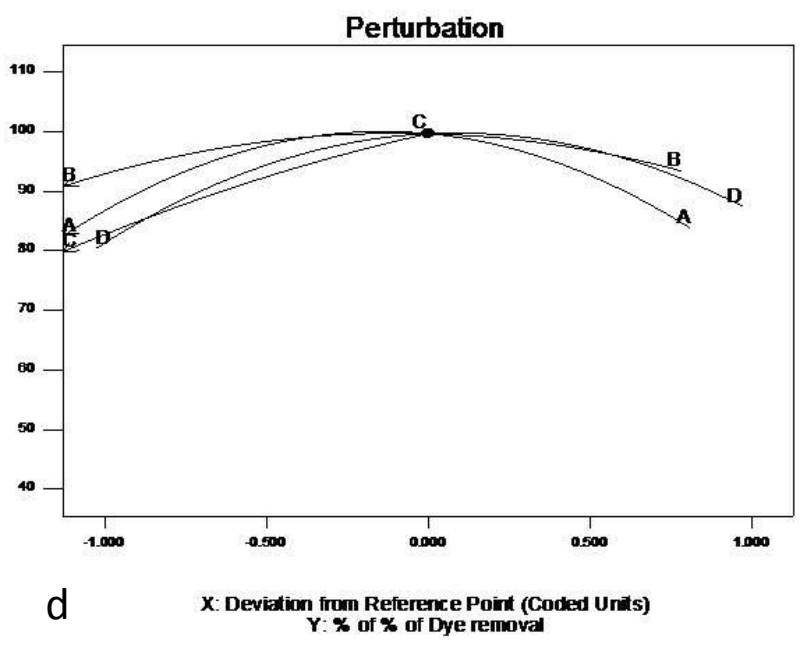

Figure 2. a. Three-dimensional standard error plot for dye removal by Aplanochytrium sp., b. Normal plot for the residuals and normal percentage of probability for the response of predicted and experimental values. c. Predicted and actual experimental response for the dye removal. d. perturbation plot for dye removal.

Table 4c. FTIR of malachite green dye after 24 days of removal by Aplanochytrium sp., showing peaks and their corresponding bonds and name of chemical groups.

\begin{tabular}{cll}
\hline Peak & Bond & Group \\
\hline 421.41 & & \\
441.7 & $\mathrm{~S}-\mathrm{S}$ & Sulfide groups \\
495.71 & & \\
609.51 & $\mathrm{C}-\mathrm{H}, \mathrm{S}-\mathrm{S}$ & Alkene, Polysulfides \\
653.87 & $\mathrm{CH}_{3}-\mathrm{S}$ & Thio ethers \\
1635.64 & $\mathrm{C}=\mathrm{N}, \mathrm{N}-\mathrm{H}$ bending & Imino group \\
2065.76 & Metal carbonyls & Metal carbonyls \\
2086.98 & Metal carbonyls & Metal carbonyls \\
3417.86 & $\mathrm{O}-\mathrm{H}$ stretch & Alcohol \\
\hline
\end{tabular}

laccase (Claus et al., 2002; Tavares et al., 2008). When the substrate concentration like dye increases to a certain high value, the reaction rate reaches a plateau and keeps constant even if more substrate is used (Garcia et al., 2003). Statistical methods are used to predict the optimal conditions for the maximum dye removal ( $\mathrm{Li}$ et al., 1996) and hence they were determined in the present work (Figure $3 \mathrm{~A}-\mathrm{F}$ ). Figure $3 \mathrm{~A}-\mathrm{F}$ clearly show that the dye removal efficiency increased with increasing incubation period and dose of thraustochy-trids. The effect of initial $\mathrm{pH}$ on dye removal efficiency is illustrated in Figure 3 a-f. A similar observation was previously reported for removal of malachite green dye by using Pithophora sp., Cosmarium sp. and Chlorella sp. (Daneshvar et al., 2007b; Khataee et al., 2009a; Kumar et al., 2006). But no report has been so far available for the potential of Thraustochytrids in dye removal.

The dye removal was confirmed further by Fourier Transform Infra-Red (FT-IR). The FT-IR spectra of the degraded dye and the un-degraded dye are shown in Table 4a-c and Figure $4 a$ and b. FT-IR spectra of undegraded dye showed the specific peaks in a range 


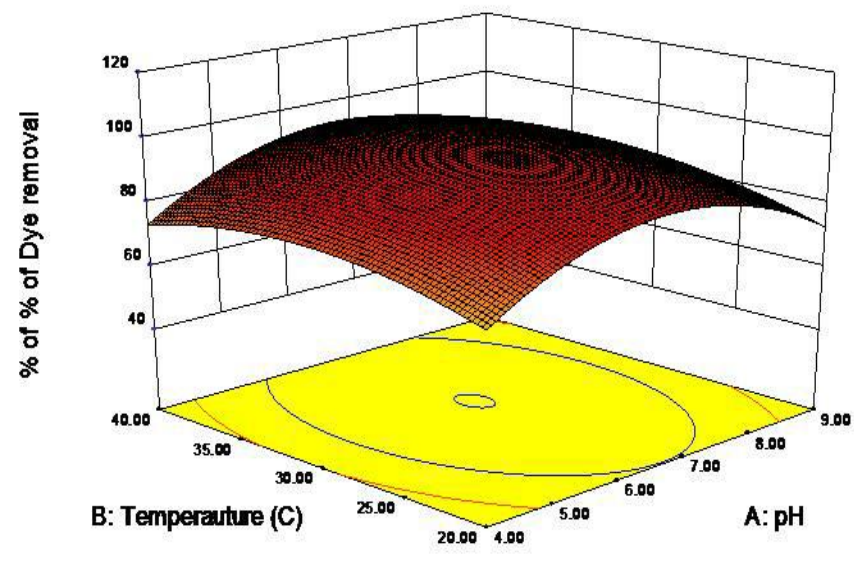

a

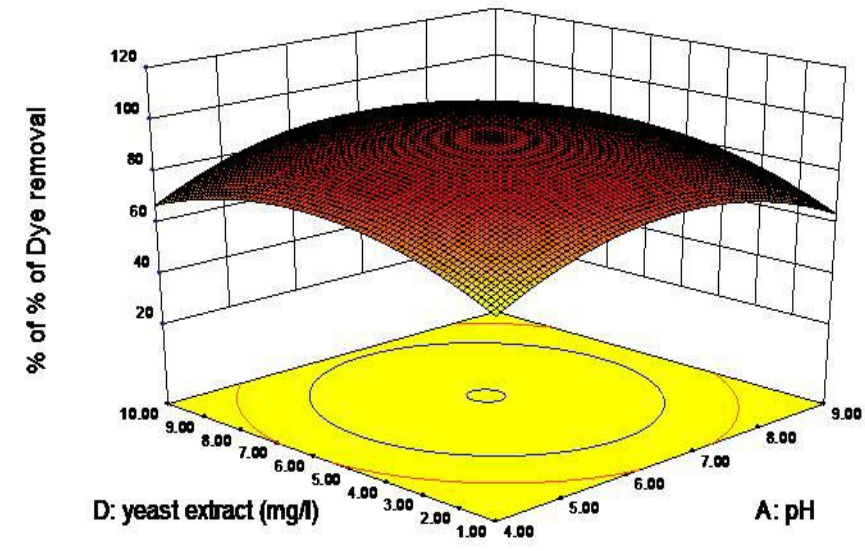

C

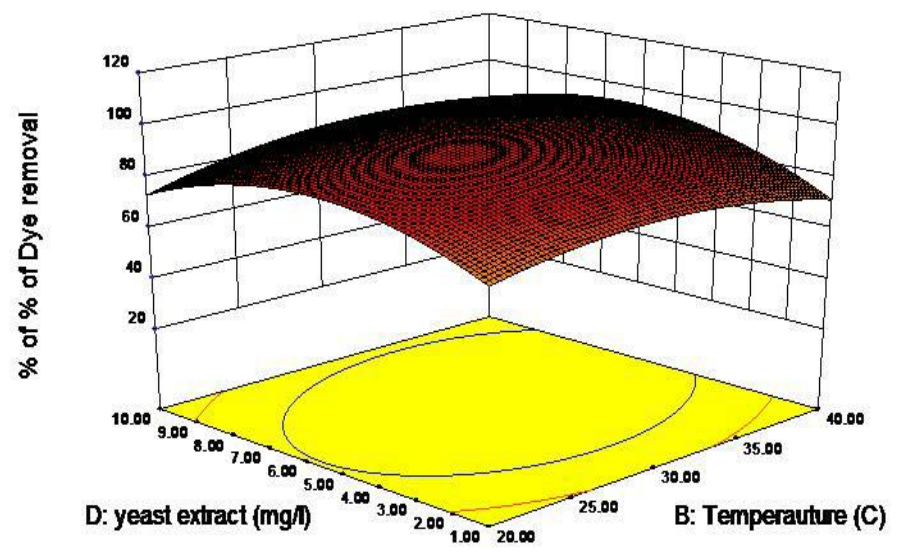

e

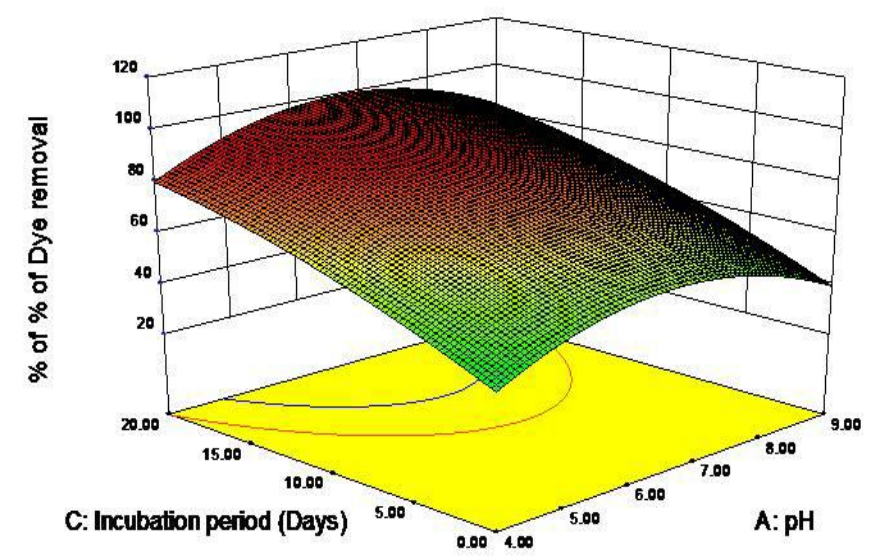

b

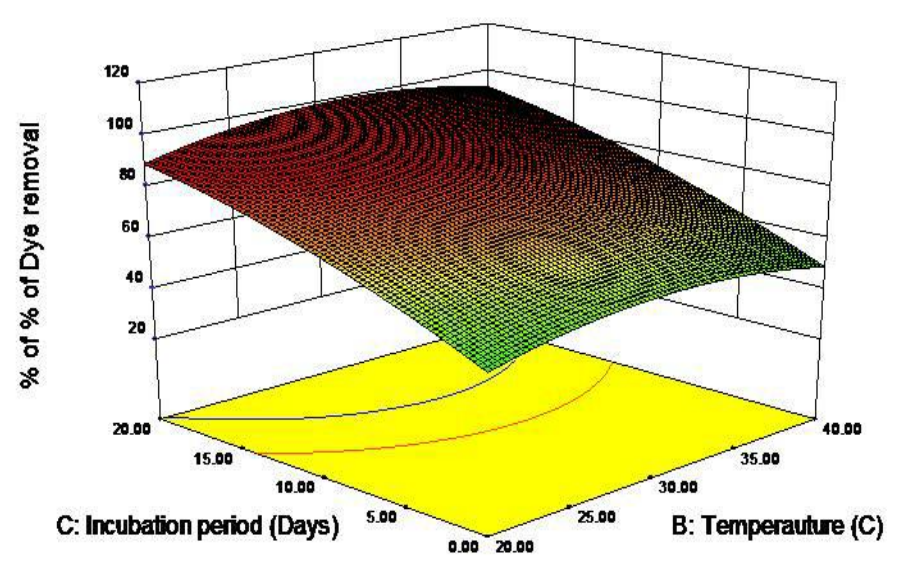

d

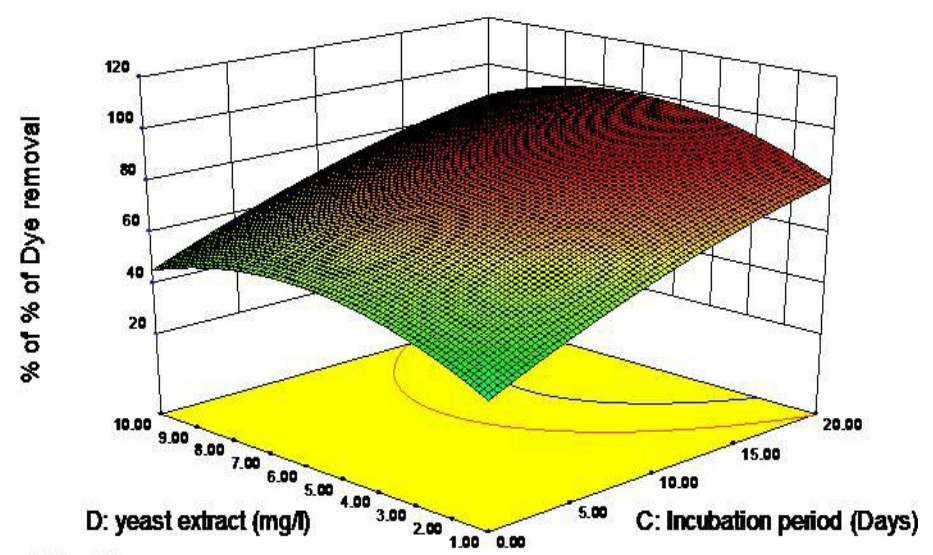

f

Figure 3. Three-dimensional response surface plot for (a) effect of temperature and $\mathrm{pH}$, (b) effect of incubation period and adsorbent dosage (mg/l), (c) effect of ferric ammonium citrate and $\mathrm{pH}$, (d) effect of incubation period and temperature, (e) effect of ferric ammonium citrate and temperature and (f) effect of ferric ammonium citrate and incubation period, on response of dye removal by Aplanochytrium sp. 


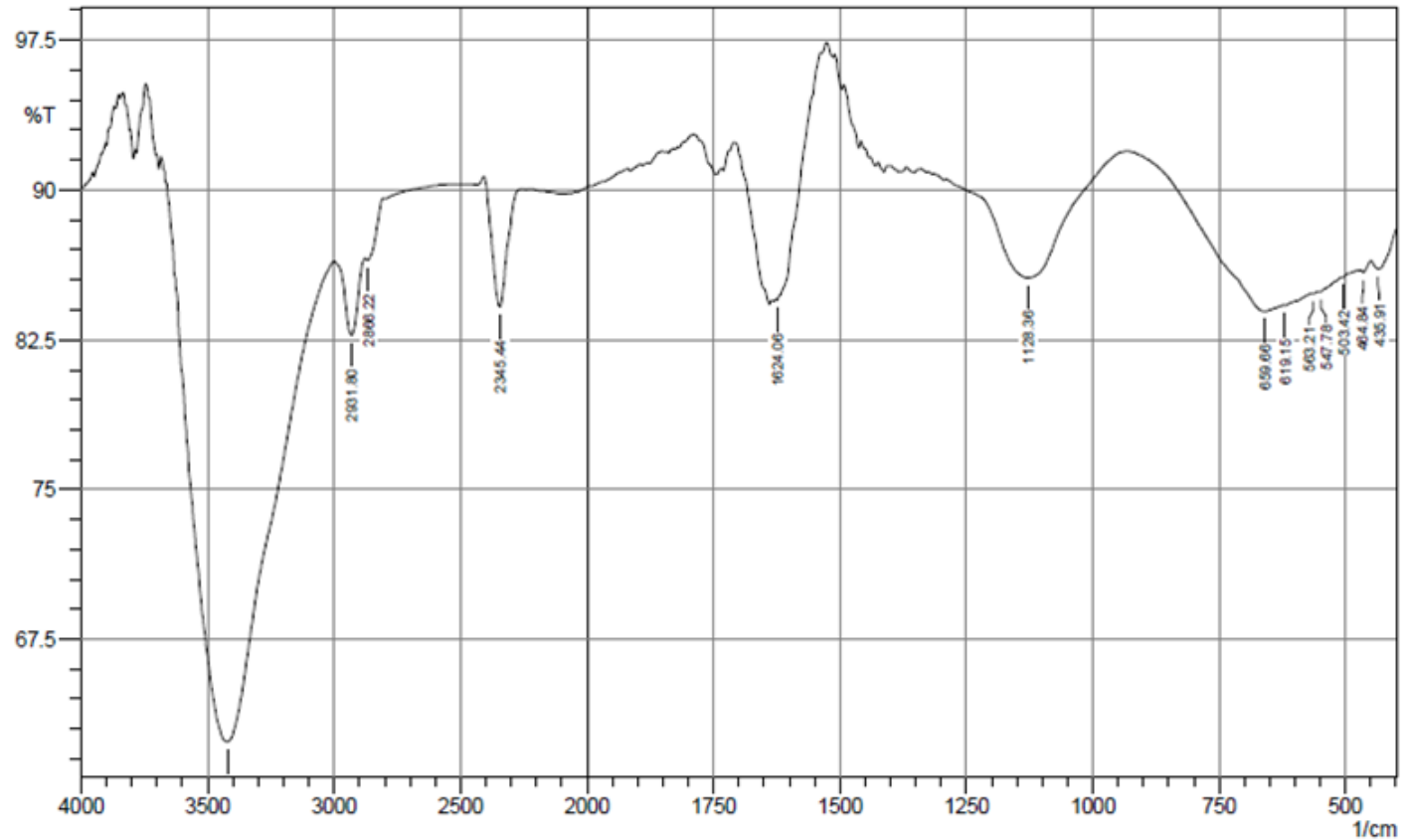

Figure 4a. FTIR spectra of malachite green before removal.

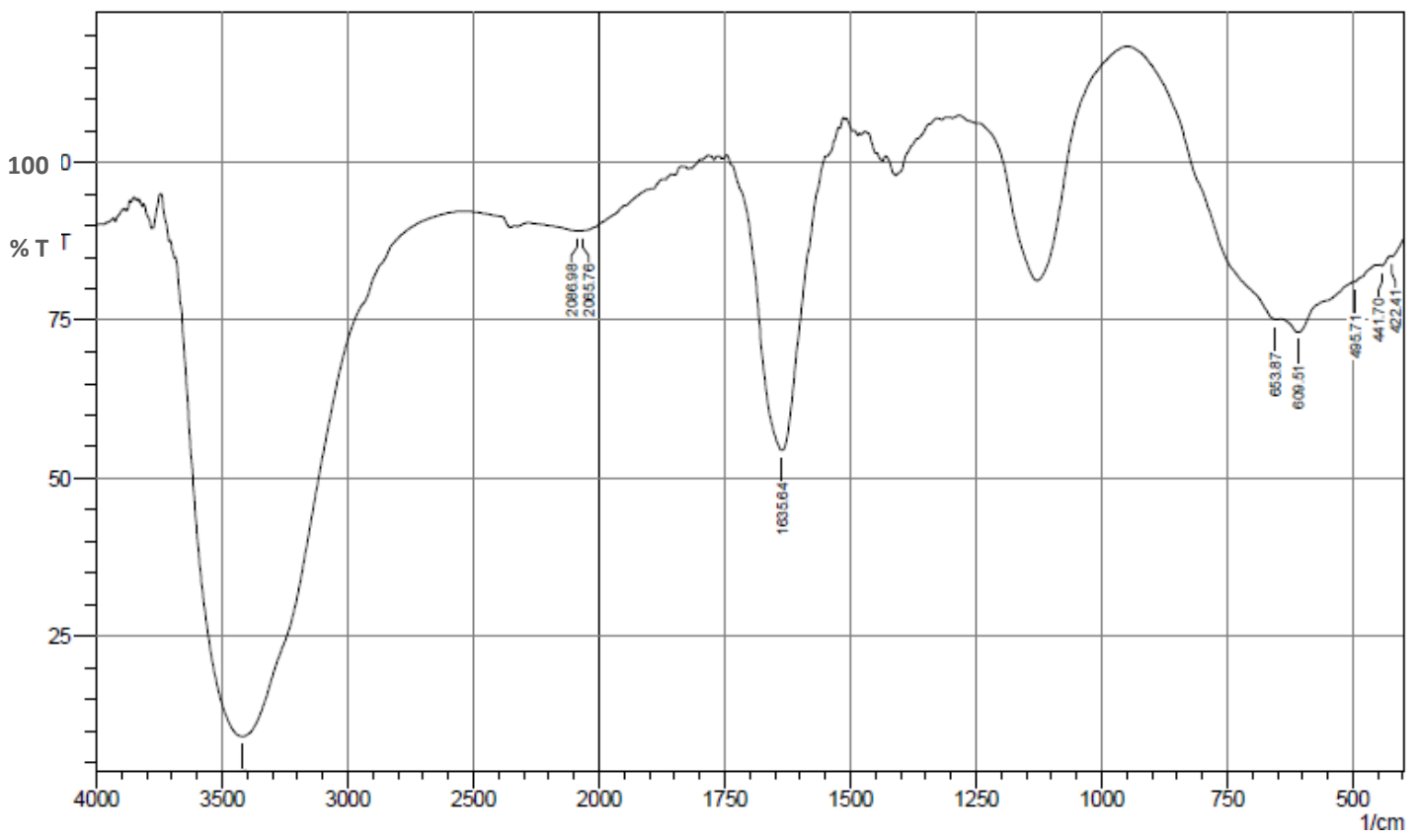

Figure 4b. FTIR spectra of malachite green after removal with Aplanochytrium sp.

between 1500 and $500 \mathrm{~cm}^{-1}$ for the mono and para-di substituted benzene rings. The peaks between 400 and $550 \mathrm{~cm}^{-1}$ represent the presence of sulfide groups and bromine groups. Also, the peak at $1128.36 \mathrm{~cm}^{-1}$ for the C$\mathrm{N}$ stretching vibrations and peak at $2931 \mathrm{~cm}^{-1}$ for $\mathrm{C}-\mathrm{H}$ stretching of asymmetric- $\mathrm{CH}_{3}$ group gives the perception of structure of malachite green. The $\mathrm{O}-\mathrm{H}$ stretching (3421.72) confirmed the alcoholic groups. The peaks at $1624 \mathrm{~cm}^{-1}$ for the $\mathrm{C}=\mathrm{N}$ stretching. The peaks of the degraded dye were compared with un-degraded dye. There were 13 peaks in un-degraded dye as against only 9 peaks in degraded dye. 
The FT-IR spectra of degraded dye showed peak at $1635 \mathrm{~cm}^{-1}$ for $\mathrm{C}=\mathrm{N}$ - stretch and $\mathrm{N}-\mathrm{H}$ bends represents the formation of primary and secondary amines. The sharp peaks of un-degraded dye at 2300 to $2900 \mathrm{~cm}^{-1}$ for di substituted benzene derivatives indicate the aromatic nature of amines which were completely degraded by Aplanochytrium sp. This prompted the proposal of the possible mechanism for the removal of aromatic amines in the dye. The triple bonded compounds of degraded dye in the malachite green might have reacted with carbonyl compounds present in Aplanochytrium sp. The addition of carbon into triple bonded compounds might have cleaved the bonds to form double bonded and single bonded compounds.

\section{REFERENCES}

Balakrishnan Priya, Lakshmanan Uma, Abdul Khaleel Ahamed, Gopalakrishnan Subramanian, Dharmar Prabaharan (2011). Ability to use the diazo dye, C. I. Acid Black 1 as a nitrogen source by the marine cyanobacterium Oscillatoria curviceps. Bioresour. Technol. (article in press).

Balamurugan B, Thirumarimurugan M, Kannadasan T (2011). Anaerobic removal of textile dye bath effluent using Halomonas sp., Bioresour. Technol. 102:6365-6369.

Bali U, Atalkaya E, Sengl F (2004). Photoremoval of reactive black 5, direct red 28 and direct yellow 12 using UV, $U \mathrm{UV}_{2} \mathrm{O}_{2}$ and UV/ $\mathrm{H}_{2} \mathrm{O}_{2} / \mathrm{Fe}^{2+}$ : A comparative study. J. Hazard. Mat. 114:159-166.

Behnajady MA, Modirshahla N, Hamzavi R (2006). Kinetic study on photocatalytic removal of $\mathrm{C}$. I. Acid Yellow 23 by $\mathrm{ZnO}$ photocatalyst. J. Hazard. Mater. 133:226-232.

Chetan CO, Harshal NN, Preeti MM, Milind SP, Ranjit RH, Kachru RG (2011). Mechanistic investigation of decolorization and removal of reactive red 120 by Bacillus lentus. Bioresour. Technol. 102:758-764.

Claus H, Faber G, Konig H (2002). Redox-mediated decolorization of synthetic dyes by fungal laccases. Appl. Microbiol. Biotechnol. 59:672-678.

Daneshvar N, Khataee AR, Rasoulifard MH Pourhassan M (2007). Bioremoval of dye solution containing Malachite Green: Optimization of effective parameters using Taguchi method. J. Hazard. Mater. 143:214-219.

Garcia O, Camarero S, Colom J, Martinez AT, Martinez MJ, Monje R, Vidal T (2003). Optimization of a laccase-mediator stage for TCF bleaching of flax pulp. Holzforschung 57:513-519.

Gomathi V (2009). Studies on Thraustochytrids of mangrove sediments for polyunsaturated fatty acids and nanoparticles synthesis. M. Phil., Thesis, Annamalai University, Parangipettai, Tamilnadu, India. pp. 63-65.

Guo JB, Zhou JT, Wang D, Tian CP, Wang P, Uddin MS, Yu H (2009). Biocatalyst effects of immobilized Anthraquinone on the anaerobic reduction of azo dyes by the salt-tolerant bacteria. Water Res. 41:426.
Khataee AR, Ayazloo M, Pourhassan M (2009). Biological decolorization of C. I. Basic Green 4 solution by Chlorella sp. effect operational parameters. Chin. J. Appl Environ. Biol. 15:110-114.

Korbahti BK, Rauf MA (2008). Application of response surface analysis to the photolytic removal of basic red 2 dye. Chem. Eng. J. 138:166171.

Kumar K, Saravana Devi S, Krishnamurthi K, Gampawar S, Mishra N, Pandya G, Chakrabarti T (2006). Decolorisation, bioremoval and detoxification of benzidine based azo dye. Bioresour. Technol. 97:07413.

Lamia A, Abdelkarim M, Abdelkarim C, Amina B (2011). Decolorization and removal of azo dye methyl red by an isolated Sphingomonas paucimobilis: Biotoxicity and metabolites characterization. Desalination 274:272-277.

Li J, Nagpal P, Vitart V, McMorris TC, Chory J (1996). A role for brassinosteroids in light-dependent development in Arabidopsis. Science 272:398-401.

Mohammadian M, Fazli AR, Mesdaghinia K, Naddafi S, Nasseri M, Yunesian M, Mazaheri A, Rezaie S, Hamzehei H (2010). Optimization of reactive blue 19 decolorization by Ganoderma sp. using response surface ethodology. Iran. J. Environ. Health Sci. Eng. 7(1):35-42.

Montgomery SL (1997). Permian bone spring formation: sandstone play in the Delaware basin, Part II-Basin. Am. Assoc. Pet. Geol. Bull. 81(9):1423-1434.

Parikh A, Madamwar D (2005). Textile dye decolorization using Cyanobacteria. J. Coll. Interf. Surf. 352:102-108.

Peralta-Hernandez JM, Meas-Vong Y, Rodriguez FJ, Chapman TW, Maldonado MI, Godinez LA (2008). Comparison of hydrogen peroxide-based processes for treating dye-containing wastewater: decolorization and destruction of orange II azo dye in dilute solution. Dyes Pigm. 76:656-662.

Plackett RL, Burman JP (1946). The design of optimum multifactorial experiments. Biometrika 33:305-325.

Saratale RG, Saratale GD, Chang JS, Govindwar SP (2010). Decolorization and bioremoval of reactive dyes and dye wastewater by a developed bacterial consortium. Bioremoval 10:1007-1012.

Tavares APM, Cristovao RO, Loureiro JM, Boaventura RAR, Macedo EA (2008). Optimisation of reactive textile dyes removal by laccasemediator system. J. Chem. Technol. Biotechnol. 83:1609-1615.

Tony BD, Goyal D, Khanna S (2009a). Decolorization of textile azo dyes by aerobic. Afr. J. Microbiol. Res. 5(15):2187-2197.

Tony BD, Goyal D, Khanna S (2009b). Decolorization of direct red 28 by mixed bacterial culture in an up-flow immobilized bioreactor. $\mathrm{J}$. Microbiol. Biotechnol. 36:955.

Wenzhong T, Rong J, Dongqing Z (2011). Decolorization and removal of synthetic dyes by Schizophyllum sp. F17 in a novel system. Desalination 265:22-27. 